\title{
Obstetric outcome study of oligohydramnios beyond 34 completed weeks of gestation
}

\author{
Hema K. R. ${ }^{1 *}$, Lalitha H. S. ${ }^{2}$
}

\begin{abstract}
${ }^{1}$ Department of Obstetrics and Gynecology, Sri Siddhartha Medical College, Tumkur, Karnataka, India
${ }^{2}$ Department of Obstetrics and Gynecology, Sree Nursing Home, Tumkur, Karnataka, India
\end{abstract}

Received: 13 August 2018

Accepted: 18 August 2018

*Correspondence:

Dr. Hema K. R.,

E-mail: drhema78@gmail.com

Copyright: (c) the author(s), publisher and licensee Medip Academy. This is an open-access article distributed under the terms of the Creative Commons Attribution Non-Commercial License, which permits unrestricted non-commercial use, distribution, and reproduction in any medium, provided the original work is properly cited.

\section{ABSTRACT}

Background: Perinatal morbidity and mortality are significantly increased when oligohydramnios is present. As the amniotic fluid volume decreases, the perinatal mortality rate increases. The incidence of major congenital anomalies with IUGR also increases as the amniotic fluid volume declines. There is a close association between declining placental function in the latter part of the third trimester and amniotic fluid volume1. Thus, post term patients are at a greater risk for development of oligohydramnios. Fetal anomalies that results in oligohydramnios classically involve the urinary tract. The most frequently mentioned renal anomalies include bilateral renal agenesis, multicystic dysplastic kidneys, bladder outlet obstruction and infantile polycystic kidneys.

Methods: All antenatal patients seen in the Department of Obstetrics and Gynecology at Sri Siddhartha Medical College and Research Centre between January 2015 to January 2017, who were willing to participate in the trial study were enrolled. Ultrasound GE Voulson S8-PRO equipped with $3.5 \mathrm{MHz}$ transducer was used to measure the amniotic fluid index. The AFI in each group was noted and the pregnancy outcome in each group was determined. At the time of delivery following data variables were collected and compiled.

Results: There were 105 women, who were divided into three groups of 35 each. Those women with AFI $<5$ had more chances of emergency caesarian section, the causes were fetal distress with variable and late fetal heart decelerations. The incidence of meconium stained liquor and NICU admission were more.

Conclusions: The women with AFI $<5$ had more chances of emergency caesarian section, the causes were fetal distress with variable and late fetal heart decelerations. Amniotic Fluid Index is a valuable screening test for detecting fetuses that may have poor perinatal outcome.

Keywords: AFI, Fetal anomalies, Ultrasound GE Voulson S8-PRO

\section{INTRODUCTION}

The importance of amniotic fluid volume as an indicator of fetal status was appreciated relatively recently. ${ }^{2}$ Amniotic fluid plays a major role in the fetal growth and development of fetus. It provides a medium, in which the fetus can readily move, cushions the fetus against possible injuries and helps maintain an even temperature. It may also have a role in dilatation of cervix during labor. It helps to maintain the fetal body temperature and place a part in the homeostasis of fluid and by permitting extensions of the limbs it prevents joint contractures. ${ }^{3,4}$ It prevents compressions of the umbilical cord and placenta and thus protects the fetus from vascular and nutritional compromise. The abnormalities of the fluid volume can thus interfere directly with fetal development or may be an indirect sign of underlying disorder. The progressive improvements in ultrasonographic imaging have to take 
the technology of fetal and amniotic fluid assessment from the stage of subjective impression to present state in which relatively sophisticated judgments of fetal condition can be based on reproducible measurements. In present practice, semi quantitative amniotic fluid volumes assessment during routine ultrasound examination and antipartum testing has become the standard of care.

Oligohydramnios is referred less than the 5th percentile for gestational age. Incidence: Oligohydramnios affects approximately $3.9 \%$ of all pregnancies. According to Phelan ${ }^{5}$, the likelihood of a low AFI $(\leq 5 \mathrm{~cm})$ between 36 - 40 weeks gestation was $2.4 \%$. Mark and Divon ${ }^{6}$ found oligohydramnios in $12 \%$ of 511 pregnancies at 41 weeks or later.

\section{Causes of oligohydramnios}

\section{Fetal}

- Chromosomal abnormalities.

- Congenital anomalies.

- Growth restrictions.

- Intrauterine fetal demise.

- Post term pregnancies.

- $\quad$ Ruptured membranes.

\section{Maternal}

- Utero placental insufficiency.

- Hypertension.

- Pre-eclampsia.

- Diabetes.

\section{Placenta}

- Abruption.

- Twin-Twin transfusion.

\section{Drugs}

- Prostaglandin synthetase inhibitors.

- Angiotensin converting enzyme inhibitors.

\section{Idiopathic}

- $10 \%$.

\section{Iatrogenic}

- $\quad$ Following amniocentesis or CVS ( $<1 \%$ incidence).

\section{Congenital anomalies associated with oligohydramnios}

\section{Genito urinary}

- Renal agenesis.

- Ureteral obstruction.

- Bladder exstrophy.

- Prune belly syndrome.

- $\quad \mathrm{B} / \mathrm{L}$ multi-cystic dysplastic kidney.
- Meckel- Gruber syndrome.

- Ureteropelvic junction obstruction.

Non-renal

Cardiac

- Congenital heart block.

- Fallot's tetralogy.

- Septal defects.

Hypothyroidism

- Skeletal.

- Syringomyelia.

- Sacral agenesis.

- Absent radius.

- Facial clefting.

CNS

- Holoprosencephaly.

- Meningocele.

- Encephalocele

- Microcephaly.

Cloacal dysgenesis

Cystic hygroma

Diaphragmatic hernia

TRAP (Twin reverse arterial perfusion)

- $\quad$ Sequence and twin - twin transfusion.

Vacterel

- Vertebral, anal, cardiac, trachea-oesophageal, renal, limb association.

Acute maternal hypovolemia is an unusual cause of oligohydramnios. ${ }^{7}$ Prostaglandin synthetase inhibitors are effective in the treatment of preterm labour and they have been shown to reduce human fetal and neonatal urinary output. Hence, prostaglandin synthetase inhibitors have also been used in the treatment of symptomatic polyhydramnios. $^{8}$ The primary fetal side effects of maternal indomethacin or other prostaglandin inhibitor therapy include closure of the ductus arteriosus and oligohydramnios. Therefore, serial ultrasound examination to assess amniotic fluid volume and the fetal ductus are warranted whenever late second or third trimester pregnant women are placed on a prostaglandin synthetase inhibitor.

Oligohydramnios is a frequent finding in a hypertensive woman with intrauterine growth retardation. ${ }^{9}$ Acute decreases in amniotic fluid volume may signal worsening of maternal hypertension and declining of placental 
function. Causes of second trimester olighydramnios are the same as for the third and include fetal urinary tract anomalies, rupture of membranes and placental insufficiency. ${ }^{10}$

Perinatal morbitity and mortality are significantly increased when oligohydramnios is present. As the amniotic fluid volume decreases, the perinatal mortality rate increases. The incidence of major congenital anomalies with IUGR also increases as the amniotic fluid volume declines. Largew et al reported that after 41 weeks of gestation, the chance of developing oligohydramnios within the next four days was $13.5 \%$ and $2.6 \%$ with amniotic fluid indices of $5.1-8.0 \mathrm{~cm}$ and $8.1-15.0 \mathrm{~cm}$ respectively. ${ }^{11}$ In a comparable growth of term pregnancies the prevalence of oligohydramnios four days after an amniotic fluid index of 5.1-8.0 cm was only $5.4 \%$.

The end points used to judge perinatal outcome includes the following.

- Perinatal death.

- Fetal distress.

- Five-minute APGAR score $<7$ was considered abnormal.

- The frequency of admission to a neonatal intensive care unit.

- IUGR.

The aims and objectives of the study are to determine the outcome of pregnancies with ultrasonographically detected normal liquor, low normal liquor and oligohydramnios and to determine the perinatal outcome in pregnancies with normal liquor, low normal liquor and oligohydramnios groups. Oligohydramnios has been identified with intrauterine growth retardation for quite some time. The basis for this association has been derived from the animal model. Experimental hypoxia results in a reflex redistribution of cardiac output i.e. renal and pulmonary blood flow decreases. Hence, urinary output and the production of amniotic fluid declines. Deutinger et al have shown that the hourly fetal urine production rate normally increases from $5.9 \mathrm{ml}$ in the $28 \mathrm{th}$ week of gestation to $26.8 \mathrm{ml}$ in the $40^{\text {th }}$ weeks. ${ }^{12}$

\section{METHODS}

All antenatal patients seen in the department of obstetrics and gynecology at Sri Siddhartha Medical College and Research Centre between January 2015 to January 2017, who were willing to participate in the trial study were taken for the study.

\section{Sample size}

- Group 1: Oligohydramnios-35.

- Group 2: Low normal-35.

- Group 3: Normal-35.

- Total-105.

\section{Inclusion criteria}

- All antenatal women of $>34$ weeks were willing to participate in the trial were included in the study.

- Antenatal women $>34$ weeks with normal amniotic fluid levels were taken as control for the study.

- Informed consent was taken for participating in the trial.

\section{Exclusion criteria}

- Pregnant women with gestation age $\leq 34$ weeks.

- Polyhydramnios.

- Multiple Pregnancy.

- Placenta Previa.

- Fetal congenital anomalies.

- Patients with ruptured membranes

Ultrasound GE Voluson S8-PRO equipped with $3.5 \mathrm{MHz}$ transducer was used to measure the amniotic fluid index. Amniotic index was measured by placing the patient in the supine position. The uterus was divided into four quadrants using the maternal sagittal midline vertically and an arbitrary transverse line approximately midway between the pubic symphysis and the upper edge of the uterine fundus the transducer was kept parallel to maternal sagittal plane and perpendicular to the maternal coronal plane. The deepest, unobstructed clear pocket of amniotic fluid was visualized and image was frozen. The ultrasound caliper was manipulated to measure the pocket in a strictly vertical direction. The process was repeated in each of the four quadrants of the uterus and all the four pockets of measurements were summed together to determine the amniotic fluid index. If the AFI was less than $8 \mathrm{~cm}$, the four quadrants evaluation was performed 3 times and the average of values were taken. The AFI in each group was noted and the pregnancy outcome in each group was determined.

Table 1: Diagnostic criteria of the amniotic fluid index.

\begin{tabular}{|ll|}
\hline Amniotic Fluid Volume & AFI Values \\
Oligohydramnios & $\leq 5 \mathrm{~cm}$ \\
Low Normal & $5.1-8.0 \mathrm{~cm}$ \\
Normal & $8.1-20 \mathrm{~cm}$ \\
Polyhydramnios & $>20 \mathrm{~cm}$ \\
\hline
\end{tabular}

At the time of delivery following data variables were collected and compiled:

- $\quad$ Presence of moderate or thick meconium

- Abnormal intrapartum fetal heart rate decelerations

- Cesarean delivery for fetal distress

- Neonatal mortality and morbidity.

\section{RESULTS}

The perinatal outcome of 3 groups 35 patients each with AFI less than $5 \mathrm{~cm}, 5.1-8 \mathrm{~cm}$ and more than $8 \mathrm{~cm}$ is 
presented here. The patients in the study group have fulfilled the entry criteria by having amniotic fluid volume measured and were delivered in present hospital allowing outcome variable to be obtained.

Study design: A prospective clinical study; mean age distribution in AFI $<5.0$ is $23.83 \pm 2.95$. In AFI $5-8$ is $24.51 \pm 4.5$ and $\mathrm{AFI}>8$ is $21.71 \pm 3.05$.
In this study, women in the age group between 18-20 years have better liquor volume compared to age groups of $>25$ years.

Parity distribution is statistically similar in three grades of AFI. There is no significant difference between the study group and the control group.

Table 2: Gestational age in week's distribution among different AFI groups.

\begin{tabular}{|c|c|c|c|c|c|c|c|c|}
\hline \multirow{3}{*}{ GA in weeks } & \multicolumn{8}{|c|}{ AFI } \\
\hline & \multicolumn{2}{|c|}{ AFI $<5.0$} & \multicolumn{2}{|c|}{ AFI (5-8) } & \multicolumn{2}{|c|}{ AFI $>8.0$} & \multicolumn{2}{|c|}{ Total } \\
\hline & No. & $\%$ & No. & $\%$ & No. & $\%$ & No. & $\%$ \\
\hline$<37$ & 4 & 11.4 & 8 & 22.9 & 1 & 2.9 & 13 & 12.3 \\
\hline 37 and above & 31 & 88.6 & 27 & 77.1 & 34 & 97.1 & 92 & 87.6 \\
\hline Total & 35 & 100.0 & 35 & 100.0 & 35 & 100.0 & 105 & 100.0 \\
\hline
\end{tabular}

Inference: Higher gestational age in weeks is statistically associated with low AFI $<5.0$ with $\mathrm{P}=0.02736^{*}$.

Table 2 shows gestational age in weeks distribution among different AFI groups. Group-I <37 weeks are $11.4 \%$. Group-II <37 weeks are $22.9 \%$. Group-III <37 weeks are $2.9 \%$ only. There is increased incidence of term gestation in Group-III. Higher gestational age in weeks is statistically associated with low AFI $<5.0$ with $\mathrm{P}=0.02736$. Malpresentations, commonest of which were breech and oblique presentation, were not associated with variation in amniotic fluid especially.

Table 3 shows the distribution of birth weight in Group-I, group-II and group-III. Emergency caesarian section rate in each group was AFI- group-I: $34.3 \%$, group II -31.4\%, group III-22.9\%. Emergency LSCS is positively and significantly associated with the low AFI $(<5.0)$ with $p$ value $=0.03001$. Fetal distress was $5(14.3 \%)$ in group I, 2
$(5.7 \%)$ in group II and $1(2.9 \%)$ in group III. Overall fetal distress was present in $8(7.6 \%)$ cases.

Table 3: Mean pattern of birth weight in three groups.

\begin{tabular}{|lll|}
\hline AFI & \multicolumn{1}{l|}{ Birth weight $(\mathrm{kg})$} \\
\hline$<5$ & Range & Mean \pm SD \\
\hline $5-8$ & $1.65-3.60$ & $2.56 \pm 0.46$ \\
\hline$>8$ & $1.50-3.50$ & $2.62 \pm 0.50$ \\
\hline Total & $1.70-3.70$ & $2.77 \pm 0.46$ \\
\hline P value & $1.50-3.70$ & $2.65 \pm 0.48$ \\
\hline
\end{tabular}

Distribution of IUGR in all 3 groups: Group I-20\% group II-17\%, and group III no case of IUGR. Presence of IUGR is positively, significantly associated with low AFI $(<5.0)$ with $\mathrm{p}$ value $=0.0080$.

Table 4 shows NICU admissions, Apgar $<7$ at $5 \mathrm{~min}$, induced labour in each group.

Table 4: Other factors according to AFI groups.

\begin{tabular}{|c|c|c|c|c|c|c|c|c|c|}
\hline \multirow{3}{*}{ Factors } & \multicolumn{8}{|c|}{ AFI } & \multirow{3}{*}{ P value } \\
\hline & \multicolumn{2}{|c|}{ AFI $<5.0(n=35)$} & \multicolumn{2}{|c|}{ AFI (5-8) $(n=35)$} & \multicolumn{2}{|c|}{ AFI $>8(n=35)$} & \multicolumn{2}{|c|}{ Total $(n=10)$} & \\
\hline & No. & $\%$ & No. & $\%$ & No. & $\%$ & No. & $\%$ & \\
\hline NICU & 5 & 14.3 & 3 & 8.6 & 0 & 0 & 8 & 7.6 & 0.0779 \\
\hline Apgar $<7$ at $5 \mathrm{~min}$ & 3 & 8.6 & 1 & 2.9 & 0 & 0 & 4 & 3.8 & 0.1270 \\
\hline Induced labour & 2 & 5.7 & 1 & 2.9 & 0 & 0 & 3 & 2.9 & 0.602 \\
\hline
\end{tabular}

\section{DISCUSSION}

Amniotic Fluid volume (AFV) is now recognized as an important marker of fetal wellbeing. In the present study
AFV was assessed by ultrasonography using Amniotic Fluid Index method (AFI). Authors studied 105 women comprising of 3 groups 35 women each with ultrasonologically detected normal liquor, low normal and oligohydramnios to determine the neonatal outcome. 
The amniotic fluid during labour in each group where as follows. Group I AFI $\leq 5$, Group II 5.1-8, and Group III where AFI more than 8 . The mode of delivery in each Group was noted; some of the patients had spontaneous delivery. Some of them were induced when the AFI $<5$, and their biophysical profile was between 4/8-6/8. Some of them in the induced group had fetal heart rate decelerations, the late and variable where taken up for emergency caesarian section. Other causes of caesarian section were severe IUGR.

Incidence of fetal distress in patients with normal liquor, low normal liquor and oligohydramnios was studied. Baron et al reported 34\% chances of fetal distresses in oligohydramnios group, $28 \%$ chance in the low normal liquor group and $22 \%$ chances in the normal liquor group. ${ }^{15}$ Chauhan et al reported relative risk of fetal distress in patient's antepartum or intra partum Amniotic fluid Index $>5.0$ or $<5.0 \mathrm{~cm}$ is $2.2 .{ }^{13}$

Redzko et al reported increased risk of fetal acidosis in prospective observation of 84 singleton pregnancy with AFI $<5 \mathrm{~cm}(\mathrm{PH}<7.16)(\mathrm{P}=0.009)$ and abnormal of FHR $(\mathrm{P}=0.004)$ when compared to control group. In the present study incidence of fetal distress $31.4 \%, 5.7 \%$, $2.9 \%$, in oligohydramnios group, low normal and normal groups respectively. ${ }^{14}$

Incidence of low APGAR at 5 minutes $(<7 / 10)$ was studied in the study conducted by Baron et al, there was no difference in the incidence of low Apgar scores at 5 minutes $(<7)$ between three groups i.e. $0.06 \%$ in the oligohydramnios group, $0.04 \%$ in the low normal group and $0.03 \%$ in the normal group. ${ }^{15}$

Chauhan et al reported Apgar score $<7$ at 5 min to have pooled relative risk 5.2 in patients with AFI $>5$ compared to patients with AFI $<5 .{ }^{13}$ In the present study, Apgar $<7$ at $5 \mathrm{~min} 8.6 \%, 2.9 \%, 0 \%$ in Oligohydramnios, low normal group respectively. Incidence of IUGR in normal, low normal and oligohydramnios patients were studied. In the study by Baron et al, the incidence of IUGR was 9/336 $(2.7 \%), 6 / 261(2.3 \%)$ and $8 / 170(4.7 \%)$ in normal liquor, low normal liquor and oligohydramnios group respectively. ${ }^{15}$

Lo Catelli et al has reported incidence of IUGR in $13.2 \%$ and $5.5 \%$ in oligohydramnios and normal group respectively. ${ }^{16}$ In the present study $20 \%$ of IUGR in oligohydramnios group $17.1 \%$ of IUGR in low normal group was found. Presence of IUGR is positively significantly associated with low AFI $(<5)$ with $\mathrm{p}=0.0080$. In summary, the above data suggest that the incidence of IUGR was significantly increased in patient with oligohydramnios and was higher in the low normal liquor compared to the normal liquor group.

Incidence of NICU admissions were studied by Baron et al, they observed no difference in NICU admissions between these three different groups. ${ }^{15} \mathrm{He}$ observed
NICU admission incidence of 33/336 (9.8\%), 18/261 $(6.9 \%)$ and $14 / 170(8.2 \%)$ respectively for normal liquor, low normal liquor and oligohydramnios group.

Casey BM et al reported as $7 \%$ and $2 \%$ in oligohydramnios and normal group respectively $(\mathrm{P}<$ $0.001) .{ }^{17}$ In the present study NICU admission of $14.3 \%$, $8.6 \%, 0 \%$ in the oligohydramnios, low normal, normal group respectively. NICU admission is positively significantly associated with low AFI $(<5)$ with $\mathrm{P}=0.077$.

Hence present study concludes that oligohydramnios is associated with increased incidence of fetal distress low Apgar at 5 minutes and NICU admission and thus is an indicator of poor perinatal outcome.

\section{CONCLUSION}

This prosective controlled study has shown that those with AFI $<5$ had more chances of emergency section. The causes of emergency section were fetal distress with variable and late fetal heart decelerations. This study also shows increased incidence of fetal distress, IUGR, low APGR at 5 minutes $(<7)$ and NICU admission in oligohydramnios group compared to low normal and normal group.

Amniotic Fluid Index consistently demonstrated the higher sensitivity in predicting poor fetal outcome without decreasing the specificity, positive predictive value, negative predictive value or accuracy rate. The semi quantitative assessment of Amniotic fluid volume by Amniotic Fluid Index can effectively screen for IUGR and delineate population i.e. at risk for perinatal mortality and morbidity. The potential advantages of separating patients in to high and. low risk groups includes better allocation of resources in a busy labor suite, a decrease in decision to delivery time for those patients with fetal distress and the potential to improve the outcome among parturient with oligohydramnios.

In conclusion Amniotic Fluid Index is a valuable screening test for detecting fetuses that may have poor perinatal outcome.

Funding: No funding sources

Conflict of interest: None declared

Ethical approval: The study was approved by the Institutional Ethics Committee

\section{REFERENCES}

1. Crowley P, O'Herlihy CO, Boylan P. The value of ultrasound measurement of amniotic fluid ume in the management of prolonged pregnancies. BJOG: An Int J Obstet Gynaecol. 1984 May;91(5):444-8.

2. Chamberlain MB, Manning FA, Morisson 1 . Ultrasound evaluation of amniotic fluid index, the relationship of marginal and decreased amniotic fluid 
volume to perinatal outcome. Am J Obstet Gynecol. 1984;150:245-9.

3. Brace RA. Physiology of amniotic fluid volume regulation. Clin Obstet Gynecol. 1997;40:280.

4. Wallenburg HCS. The amniotic fluid: I. water and electrolyte homeostatis. J Perinat Med. 1977;5:193.

5. Phelan JP, Smith CV, Broussard P, Small M. Amniotic fluid volume assessment with the fourquadrant technique at $36-42$ weeks' gestation. J Reprod Med. 1987 Jul;32(7):540-2.

6. Marks AD, Divon MY. Longitudinal study of the amniotic fluid index in post-dates pregnancy. Obstet Gynecol. 1992 Feb;79(2):229-33.

7. Sherer DM, Cullen JB, Thompson HO, Woods JR. Transient oligohydramnios in a severely hypovolemic gravid woman at 35 weeks' gestation, with fluid reaccumulating immediately after intravenous maternal hydration. Am J Obstet Gynecol. 1990 Mar 1;162(3):770-1.

8. Kirshon B, Mari G, Moise JK. Indomethacin therapy in the treatment of symptomatic polyhydramnios. Obstet Gynecol. 1990 Feb;75(2):202-5.

9. O'brien JM, Mercer BM, Friedman SA, Sibai BM. Amniotic fluid index in hospitalized hypertensive patients managed expectantly. Obstet Gynecol. 1993 Aug;82(2):247-50.

10. Bronshtein M, Blumenfeld Z. First-and early secondtrimester oligohydramnios - a predictor of poor fetal outcome except in iatrogenic oligohydramnios post chorionic villus biopsy. Ultrasound Obstet Gynecol. 1991 Jul 1;1(4):245-9.

11. Lagrew DC, Pircon RA, Nageotte M, Freeman RK, Dorchester W. How frequently should the amniotic fluid index be repeated?. Am J Obstet Gynecol. 1992 Oct 1;167(4):1129-33.
12. Deutinger J, Bartl W, Pfersmann C, Neumark J, Bernaschek G. Fetal kidney volume and urine production in cases of fetal growth retardation. J Perinatal Med-Official J WAPM. 1987;15(3):307-15.

13. Chauhan SP, Sanderson M, Hendrix NW, Magann EF, Devoe LD. Perinatal outcome and amniotic fluid index in the antepartum and intrapartum periods: a meta-analysis. Am J Obstet Gynecol. 1999 Dec 1;181(6):1473-8.

14. Redźko S, Przepieść J, Urban J, Jóźwik M, Skotnicki MZ, Urban R. Antepartum amniotic fluid index and pregnancy outcome. Ginekologia Polska. 1998 Apr;69(4):163-7.

15. Baron C, Morgan MA, Garite TJ. The impact of amniotic fluid volume assessed intrapartum on perinatal outcome. Am J Obstet Gynecol. 1995 Jul $1 ; 173(1): 167-74$.

16. Locatelli A, Vergani $\mathrm{P}$, Toso L, Verderio M, Pezzullo JC, Ghidini A. Perinatal outcome associated with oligohydramnios in uncomplicated term pregnancies. Arch Gynecol Obstet. 2004 Jan 1;269(2):130-3.

17. Casey BM, McIntire DD, Bloom SL, Lucas MJ, Santos R, Twickler DM, et al. Pregnancy outcomes after antepartum diagnosis of oligohydramnios at or beyond 34 weeks' gestation. Am J Obstet Gynecol. 2000 Apr 1;182(4):909-12.

Cite this article as: Hema KR, Lalitha HS. Obstetric outcome study of oligohydramnios beyond 34 completed weeks of gestation. Int J Reprod Contracept Obstet Gynecol 2018;7:3857-62. 